\title{
A Study on Muscle Fatigue Associated with Awkward Posture Among Workers in Aerospace Industry
}

\author{
Seri Rahayu K. ${ }^{1, a}$, Norhidayah $\mathrm{H}^{2, \mathrm{~b}}$ and Shahrizan M.O., \\ 1,2,3 Faculty of Manufacturing Engineering, \\ Universiti Teknikal Malaysia Melaka, Durian Tunggal, 76100 Melaka, Malaysia \\ Phone: +606-3316002, Fax: +606-3316411 \\ a seri@utem.edu.my, b norhidayah_hashim@ymail.com, c mshahrizan@utem.edu.my
}

\section{Keywords: Awkward Posture, Muscle Fatigue, Myoelectric Level and Lay-up Process}

\begin{abstract}
In aerospace industry, many tasks required manufacturing workers to perform their works in awkward posture. Awkward posture is a practical working posture when joints are not in neutral position such as lifting heavy products, reaching materials, bending forward their back when doing jobs, and pushing or pulling excessive loads because those tasks require a stable position and large degree of freedom. If the workers perform the jobs continuously in awkward posture throughout the working hours, they may be experience muscle fatigue. The objective of this study is to measure the myoelectric level $(\mu \mathrm{V})$ exerted by the right and left thoracolumbar fascia muscles while workers perform the lay-up process in aerospace industry. The myoelectric level in the muscles was measured using surface Electromyography (sEMG) measurement. Six production workers from aerospace industry participated as subjects. The muscle fatigue of the subjects was measured during beginning until finish of lay-up process. This measuring activity has been doing from Wednesday to Friday. Highest results of myoelectric level for right thoracolumbar fascia is when the workers make the lay-up process for ply seven until ply eleven. Different with the results of myoelectric level for left thoracolumbar fascia which is; three of the workers got highest result when they are making the lay-up process for ply seven until ply eleven, but the other three of the workers got highest result when they are making the lay-up process for ply twelve. Nevertheless, after averaging both of the results, a mean result for each worker shows the highest myoelectric level is when the workers make the lay-up process for ply seven until ply eleven. According to the mean, a percentage of worse tasks are projected. Based on this study, the authors concluded that muscle fatigue of the lay-up workers in aerospace industry was influenced by the work load, work activity and duration of awkward posture.
\end{abstract}

\section{Introduction}

Awkward posture can be theorized as a discomfort posture because it is harmful position for human body when a joint is not in its neutral range of postures and make muscles are either shorter or longer than resting length. When joints are exposed to postures that involve range of movement near the extreme positions, the muscles around the joint are stretched or compressed. If the exposure to extreme postures is prolonged, the muscles do not immediately return to their resting length [1]. In manufacturing workplaces, numerous processes jobs are recommended to be performed in awkward posture. For example, they need to bend their neck forward greater than 30 degrees, raise their elbow above their shoulder, bend their wrist downward with palm facing downward greater than 30 degrees, bend their back forward greater than 45 degrees, squatting, etc [2].

The surface Electromyography (sEMG) is one of the scientific instruments that have been applied to quantify muscle fatigue of workers while performing tasks in awkward posture [3-13]. The sEMG quantifies the effort level of muscle in terms of myoelectric level, expressed in micro volt $(\mu \mathrm{V})$ corresponding to contraction of the muscles while handling the jobs. For instance, if the myoelectric level is high, it means that the muscles are exerting high effort while performing the particular tasks. If the tasks are continuously performed, the muscles will fatigue. 
The purpose of this study is to quantify the effort level exerted by the right and left thoracolumbar fascia muscles among six manufacturing workers in aerospace industry (lay-up process line) while performing tasks in awkward posture. Additionally, the myoelectric level of these workers was compared to find out which activity exerted more effort in the muscles while performing the tasks.

\section{Methodology}

An aerospace company situated in Malaysia was selected to perform the data collection. In the production department of the company, all workers are males and national citizenship. They worked in two shifts based on a 12-hour shift schedule. A main process line in this company is lay-up process. All manufacturing workers performed their tasks in awkward posture especially in lay-up process line. Moreover, the tasks require workers to stand with awkward posture because the nature of jobs is repetitive, frequent movement, and large degree of freedom.

Six production workers were recruited as subjects in this study. They are selected from lay-up process lines. To fulfill the basic requirement of this study, selected workers who performed processes jobs in awkward posture and no injuries for the past 12 months were allowed to participate in the experimental work. Demographic of the selected workers from plying process line are described in Table 1.

Table 1. Demographic of the workers participated in the study.

\begin{tabular}{|l|c|}
\hline \multicolumn{1}{|c|}{ Criteria } & Mean (SD) \\
\hline Gender & Male \\
\hline Age & $25.7(5.0)$ \\
\hline Mass $(\mathrm{kg})$ & $64.5(10.9)$ \\
\hline Height $(\mathrm{cm})$ & $174.2(7.3)$ \\
\hline Experience (year) & $4.7(2.7)$ \\
\hline
\end{tabular}

A surface Electromyography (sEMG ME3000P4, MEGA Electronics, Finland) and MegaWin Software were used to record, store and analyze all the data regarding muscle fatigue of the workers. The measurements of muscle fatigue were conducted based on real time monitoring. All electrodes were connected to a data logger. The myoelectric level from the data logger is monitored through laptop screen using wireless networking. The sEMG electrodes were attached conscientiously to the subject's skin to measure the fatigue in the two muscles: right and left thoracolumbar fascia. In the measurement and analysis of awkward jobs, the selected muscles are chosen based on the statistical data analysis from questionnaire that has been answered from 22 workers before the experimental work is made. They experienced an intense pain in the lower limb of body as much as $97.22 \%$. The selected muscles are also suggested by the established guidelines [14] and a recent review article [15].

After all the measurement settings are ready, the subject can now start to perform his task. Fig. 1 shows the worker with the sEMG instruments to measure fatigue in the selected muscles.
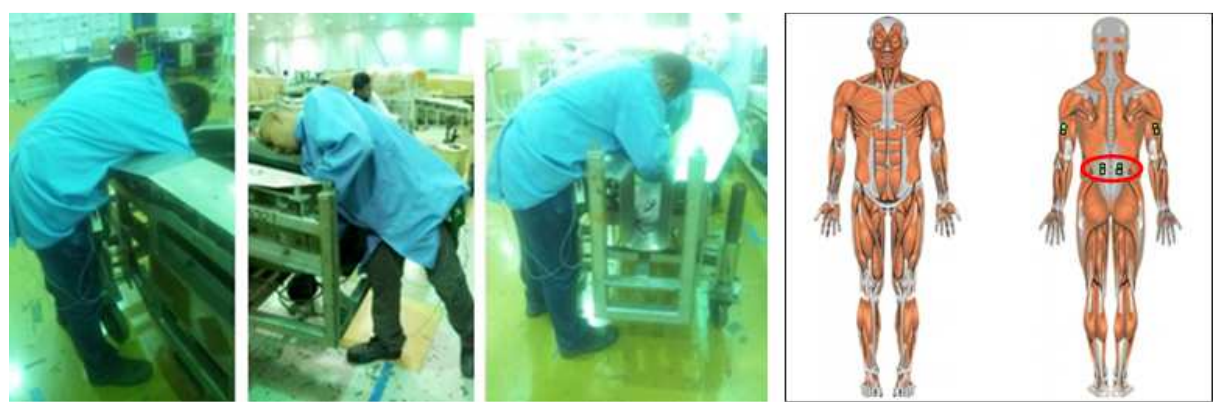

Fig. 1. Surface Electromyography instruments was setup to measure muscle fatigue in right and left thoracolumbar fascia muscle. 
In a workday, both of the muscles were concurrently measured for continuous awkward posture to quantify the effort level exerted by the muscles when they are performing their tasks. There are four tasks they need to perform which is lay-up ply one and two, lay-up ply three until ply six, layup ply seven until ply eleven, and lastly lay-up ply twelve. Each of the subjects does not have an identical time to begin or finish their work. The measuring activity was conducted on three consecutive workdays from Wednesday to Friday.

The output parameter from the sEMG measurement is myoelectric levels that are expressed in micro volt $(\mu \mathrm{V})$. Graphical analyses associated with descriptive and comparative analysis were used to interpret the data.

\section{Results and Discussion}

This study has conducted an analysis of muscle fatigue of manufacturing workers in aerospace company. In the company, a main manufacturing process is coming from lay-up process line. This lines required workers to perform jobs in awkward posture for prolonged time periods. All workers worked on a 12-h shift schedule. The shift is changed every week which is worked both; day and night shift. It was observed that the workers spent about $80 \%$ of the working hours in awkward posture to do their tasks (only standing during setup ply and sitting during breaks) throughout the 12-h working period. This is due to the activities that required the workers to move frequently with awkward posture along a mould. For instance, workers at the lay-up process lines have to reach the ply from the pallet on the table and lay-up the ply into the mould, synchronize with the size of the mould. Thus, the process would be practicable in awkward posture as it requires frequent bending forward of the workers back. This study observed that muscle fatigue occurred particularly in the lower back (thoracolumbar fascia muscle) due to above mentioned working conditions. Furthermore, there were complaint of fatigue in those body parts from the workers of plying process lines which is trapezius muscle, deltoid muscle, rhomboideus major muscle and triceps brachii muscle.

Through sEMG measurement, this study identified that the maximum of myoelectric level $(\mu \mathrm{V})$ in the right thoracolumbar fascia muscle is higher when the workers do the lay-up process for ply seven until eleven. This process required about 25 to 30 minutes completing. This process is fatigue because it's required the workers to bend forward their back more to the left side within the times without any rest. Fig. 2 shows the maximum of myoelectric level $(\mu \mathrm{V})$ of right thoracolumbar fascia muscle for each worker while they are performing the tasks.

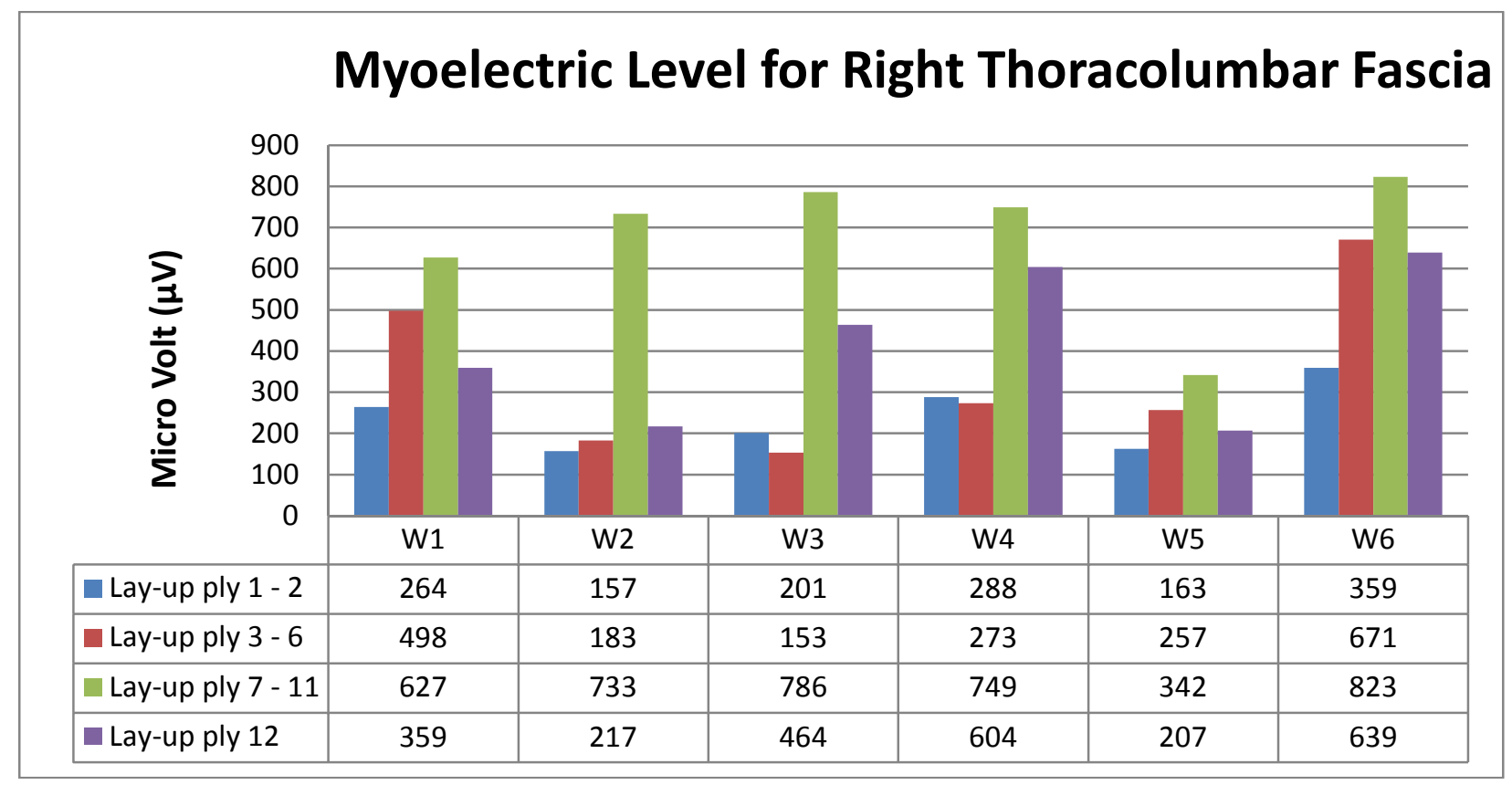

Fig. 2. Myoelectric level of right thoracolumbar fascia muscle for each worker. 
While the maximum of myoelectric level $(\mu \mathrm{V})$ in the left thoracolumbar fascia muscle is higher when the workers do the lay-up process for ply seven until eleven and lay-up process for ply twelve. Three of the worker's results are higher when they are making the lay-up process for ply seven until eleven, but the other three of the worker's results are higher when they are making the lay-up process for ply twelve. This study believed that different results of myoelectric level occurred when the postures of workers were deviated significantly from neutral position especially when the tasks required them to bend forward their back more to right or left side. Thus, placed more stress in the right lower back or the left lower back [16]. Fig. 3 shows the maximum of myoelectric level $(\mu \mathrm{V})$ of left thoracolumbar fascia muscle for each worker while they are performing the tasks.

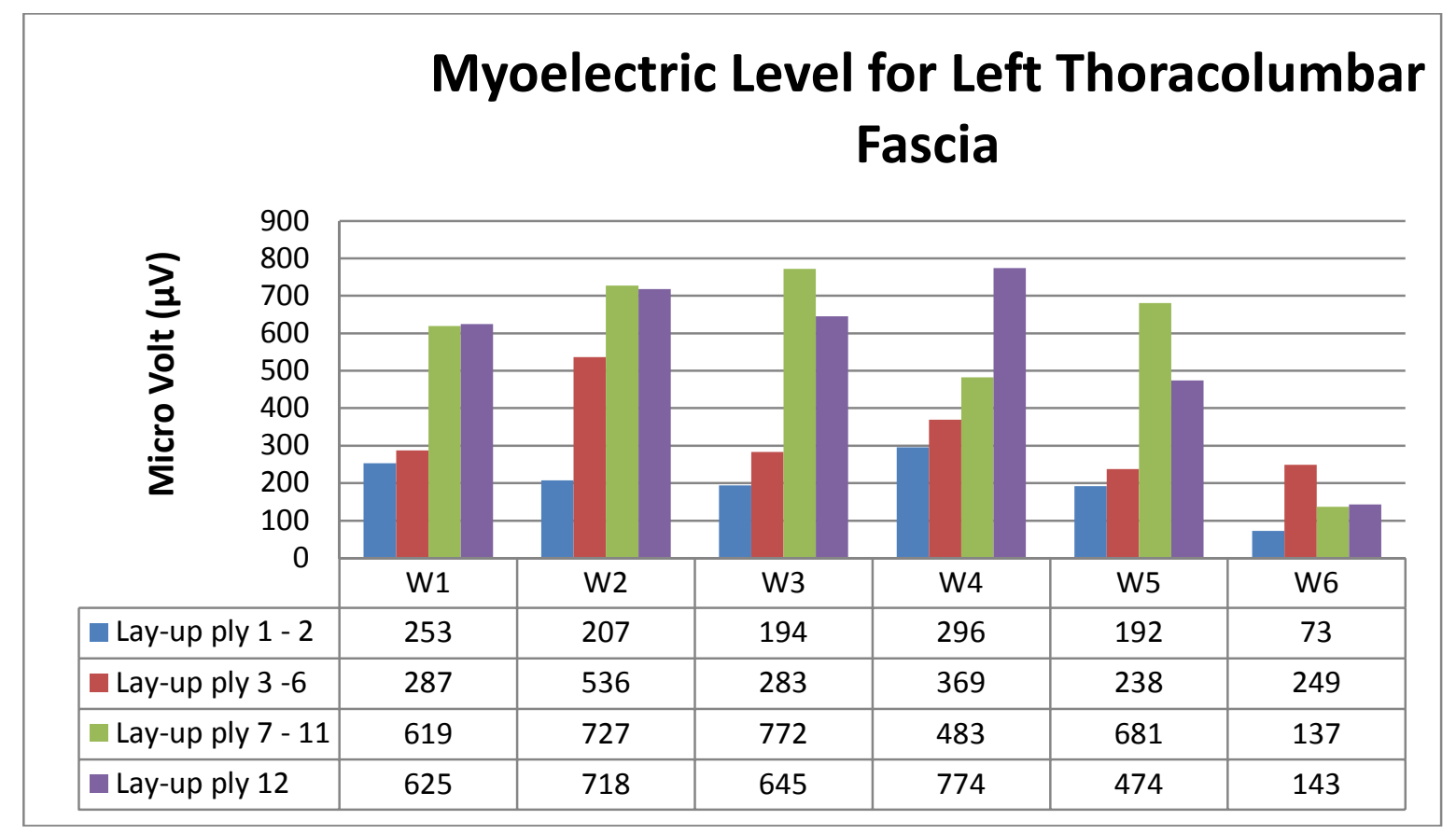

Fig. 3. Myoelectric level of left thoracolumbar fascia muscle for each worker.

Nevertheless, after averaging both of the results, a mean for each worker shows the highest result of myoelectric level are when the workers make the lay-up process for ply seven until ply eleven. This is proven the observation taken before the sEMG measurement is done. Fig. 4 shows the myoelectric level for mean of thoracolumbar fascia muscle for each worker.

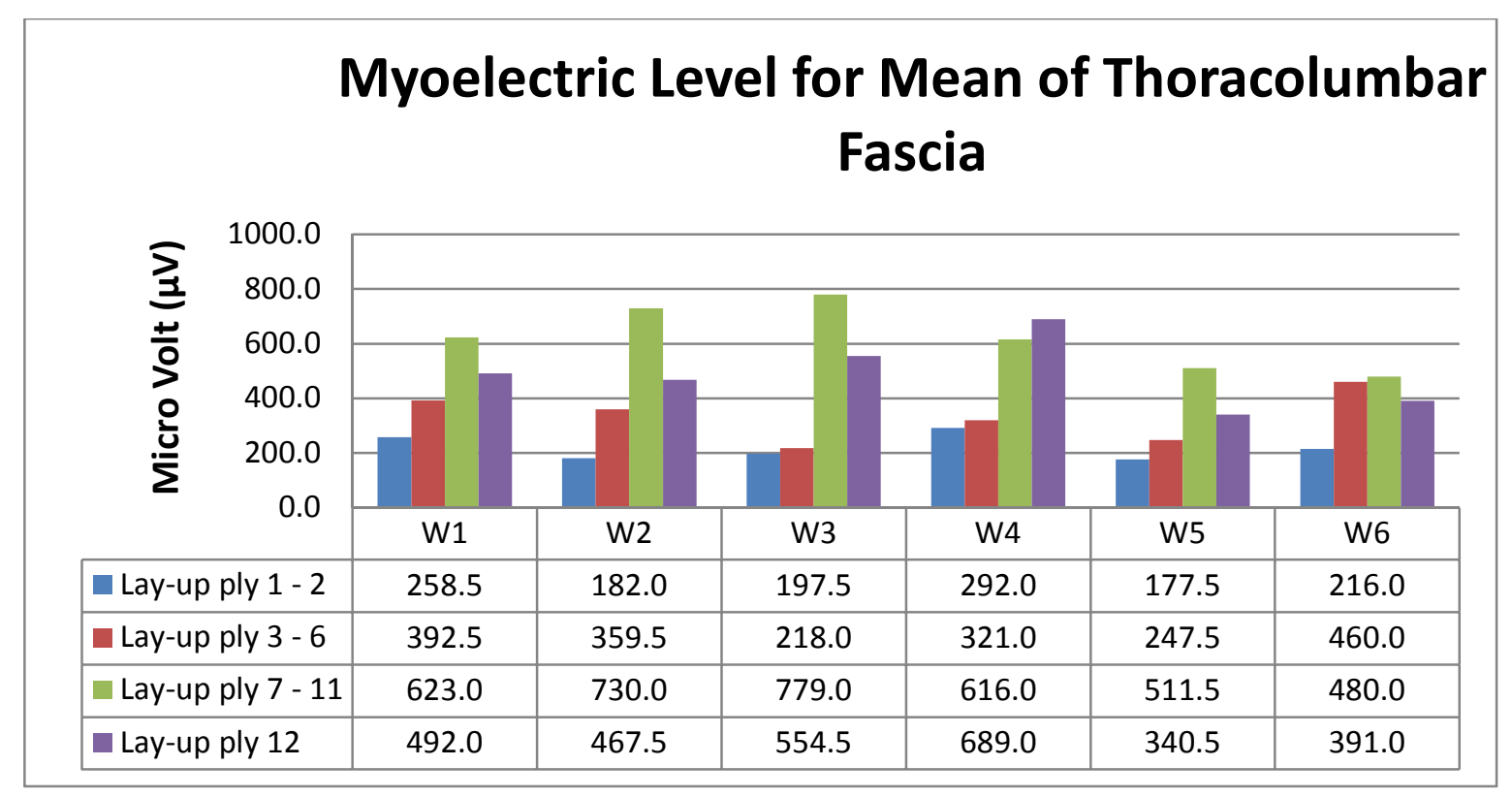

Fig. 4. Myoelectric level for mean of thoracolumbar fascia muscle for each worker. 
According to the mean, a percentage of worse tasks are projected. Based on the percentage, the fatigue tasks for lay-up workers in aerospace company can be classified. Fig. 5 shows the percentage of fatigue tasks in lay-up process lines for awkward posture according to myoelectric level $(\mu \mathrm{V})$ for mean of thoracolumbar fascia muscles.

\section{Percentage of Fatigue Tasks}

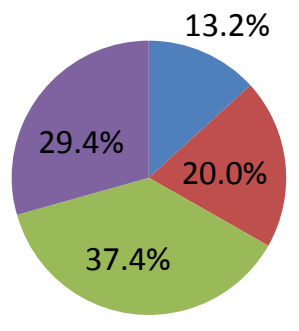

Lay-up ply 1 - 2

- Lay-up ply 3 - 6

- Lay-up ply 7 - 11

- Lay-up ply 12

Fig. 5. Percentage of fatigue tasks in lay-up process lines for awkward posture according to myoelectric level for mean of thoracolumbar fascia muscles.

This study pointed that duration of awkward posture can influenced the myoelectric level. When the worker is bending forward their back in a long period of time, static contraction of muscles can occur particularly in the back. Due to static contraction, performance of the muscles may decrease and this condition can lead to discomfort and muscle fatigue [17].

\section{Conclusion}

This study has performed muscle fatigue measurement in the right and left thoracolumbar fascia of manufacturing workers at lay-up process line in aerospace company. All workers performed their tasks in awkward posture for prolonged time periods. The measurements of muscle fatigue were conducted on four working tasks; lay-up ply one and two, lay-up ply three until six, lay-up ply seven until eleven, and lastly lay-up ply twelve. Regarding to the maximum myoelectric level of right thoracolumbar fascia, the fatigue task is when the workers do the lay-up process for ply seven until eleven. On the other hand, the maximum myoelectric level of left thoracolumbar fascia shows there are two tasks are fatigue which is when the workers do the lay-up process for ply seven until eleven, and the lay-up process for ply twelve. Therefore, this study concluded that muscle fatigue of the lay-up workers in aerospace industry was influenced by the work load, work activity and duration of awkward posture.

\section{Acknowledgement}

The authors would like to acknowledge the Ministry of Higher Education of Malaysia, the Universiti Teknikal Malaysia Melaka (UTeM), and the Centre of Research, Innovation \& Management (CRIM) UTeM for funding this research under Research Grant PJP/2012/FKP (6D) S1125. Special thank also goes to Composites Technology Research Malaysia (CTRM) Sdn. Bhd. for the permission and opportunity to facilitate a fruitful research.

\section{References}

[1] C. Hayot, A. Decatoire, J. Bernard, T. Monnet, P. Lacouture, Effects of 'posture length' on joint power in cycling, Procedia Engineering. 34 (2012) 212-217.

[2] J. T-Krajewski, L. Steiner, R. B-Limerick, Ergonomics processes: Implementation guide and tools for the mining industry, Department of Health and Human Services (NIOSH). (2009) 107110 .

[3] D. Kee, S.R. Seo, Musculoskeletal disorders among nursing personnel in Korea, International Journal of Industrial Ergonomics. 37 (2007) 207-212. 
[4] E.R. Vieira, S. Kumar, Occupational risks factor identified and interventions suggested by welders and computer numeric control workers to control low back disorders in two steel companies, International Journal of Industrial Ergonomics. 37 (2007) 553-561.

[5] A. Sheikhzadeh, C. Gore, J.D. Zuckerman, M. Nordin, Perioperating nurses and technicians' perceptions of ergonomic risk factors in the surgical environment, Applied Ergonomics. 40 (2009) 833-839.

[6] N.M. Daraiseh, S.N. Cronin, L.S. Davis, R.L. Shell, W. Karwowski, Low back symptoms among hospital nurses, associations to individual factors and pain in multiple body regions, International Journal of Industrial Ergonomics. 40 (2010) 19-24.

[7] N.K. Govindu, K. B-Reeves, Effects of personal, psychosocial and occupational factors on low back pain severity in workers, International Journal of Industrial Ergonomics. (2012) 1-7.

[8] G.P.Y. Szeto, T.K.T. Wong, R.K.Y. Law, E.W.C. Lee, T. Lau, B.C.L. So, S.W. Law, The impact of a multifaceted ergonomic intervention program on promoting occupational health in community nurses, Applied Ergonomics. 44 (2013) 414-422.

[9] K. Landau, H. Rademacher, H. Meschke, G. Winter, K. Schaub, M. Grasmueck, I. Moelbert, M. Sommer, J. Schulze, Musculoskeletal disorders in assembly jobs in automotive industry with special reference to age management aspects, International Journal of Industrial Ergonomics. 38 (2008) 561-576.

[10]R.B. Graham, M.J. Agnew, J.M. Stevenson, Effectiveness of an on-body lifting aid at reducing low back physical demands during an automotive assembly task: Assessment of EMG response and user acceptability, Applied Ergonomics. 40 (2009) 936-942.

[11]J. Hwang, Y-K. Kong, M-C. Jung, Posture evaluations of tethering and loose-housing systems in dairy farms, Applied Ergonomics. 42 (2010), 1-8.

[12]S. Meksawi, B. Tangtrakulwanich, V. Chongsuvivatwong, Musculoskeletal problems and ergonomic risk assessment in rubber tappers: A community-based study in southern Thailand, International Journal of Industrial Ergonomics. 42 (2012) 129-135.

[13]R.B. Graham, P.S. Sheppard, S. Almosnino, J.M. Stevenson, Dynamic spinal stability and kinematic variability across automotive manufacturing work shifts and days, International Journal of Industrial Ergonomics. 42 (2012) 428-434.

[14]U.S. Department of Health and Humanities Services, Selected topics in surface electromyography for use in the occupational setting: expert perspectives, U.S. National Institute for Occupational Safety and Health, Ed. (1992) 1-151.

[15]C.R. Reid, P.McC. Bush, W. Karwowski, S.K. Durrani, Occupational postural activity and lower extremity discomfort: A review, International Journal of Industrial Ergonomics. 40 (2010) 247-256.

[16] S.J. Ray, J. Teizer, Real-time construction worker posture analysis for ergonomics training, Advanced Engineering Informatics. 26 (2012) 439-455.

[17]C. Lariviere, D. Gagnon, D. Gravel, and A.B. Arsenault, The assessment of back muscle capacity using intermittent static contractions. Part 1 - Validity and reliability of electromyogrphic indices of fatigue, Journal of Electromyography and Kinesiology. 18 (2008) 1006-1019. 